\title{
On the Teaching Management Role of University Teachers
}

\author{
Teng LV ${ }^{1, a}$ and Ping $Y A N^{2, b, *}$ \\ ${ }^{1}$ School of Information Engineering, Anhui Xinhua University, Hefei 230088, China \\ ${ }^{2}$ School of Science, Anhui Agricultural University, Hefei 230036, China \\ alt0410@1693.com, bwant2fly2002@163.com \\ ${ }^{*}$ Corresponding author
}

Keywords: University Teachers, teaching Management, Basic Courses.

\begin{abstract}
University teachers should not only be the implementers of teaching, but also the main force in teaching management, which requires the recognition of all university teachers. In order to let the teachers play the role in the teaching management, the key is to make the teachers can know their important role in the whole teaching management ideologically. This paper mainly discusses the role of teachers' management from two aspects of teaching and class management.
\end{abstract}

\section{Introduction}

As an implementer of teaching, university teachers must shoulder the dual tasks of teaching and educating people. This is also the obligation and responsibility of teachers[1-3]. China's "book of Rites" said: "The so-called teacher is the person who teaches the students and also cultures the good qualities of the students." This is enough to show that teachers should teach and educate people.

As college teachers who has been teaching for many years, this paper mainly talks about the management role of teachers in teaching management from two aspects according to our years' experience in class.

\section{The Teachers of the Basic Course have a Responsibility in Class Management}

Each subject has the corresponding basic courses [4,5], which provide the learning tools and learning ideas for the follow-up courses, and is the cornerstone of the subject. If these courses are not well taught and studied, students' learning enthusiasm will be frustrated, which leads to the loss of learning the subject interest and initiative. As a result, students show interest transfer, skipping, copying homework and other negative trends, resulting in poor learning follow-up courses; on the other hand, if these basic courses can be well understood and mastered, even can be used well in real life, then it will be to stimulate the students learning enthusiasm, to further increase the learning interest and initiative of the subject, showing active learning and active thinking, benign development trend and inquisitive, and follow-up courses are also relatively easy to achieve satisfactory learning effect.

The following is a case study of computer basic courses for computer majors to illustrate the importance of teachers in teaching management.

Computer basic programming [6,7] is a public basic course for all students majoring in computer science and some students majoring in science and technology. It aims to cultivate students' computational thinking ability and practical ability to analyze and solve problems. As the computer course teachers, we find that the basic knowledge of students' interest in learning computer application depends largely on their understanding of the fundamental knowledge of computer programming, which has a great relationship with the scores of basic computer programming courses. Those who are often absent, or copy homework are nearly the students whose basic computer programming scores are under the average level. While those who actively cooperate with the teacher and often ask questions in class are almost the students whose basic computer programming scores 
are above the average level. In order to illustrate the correlation of scores of basic computer programming courses and the average grades of all professional courses of students, we randomly selected and investigated 5 parallel classes of a grade. The scores of basic computer programming courses and the average scores of all professional courses of each student were compared, which is illustrated as Figure 1-figure 5.

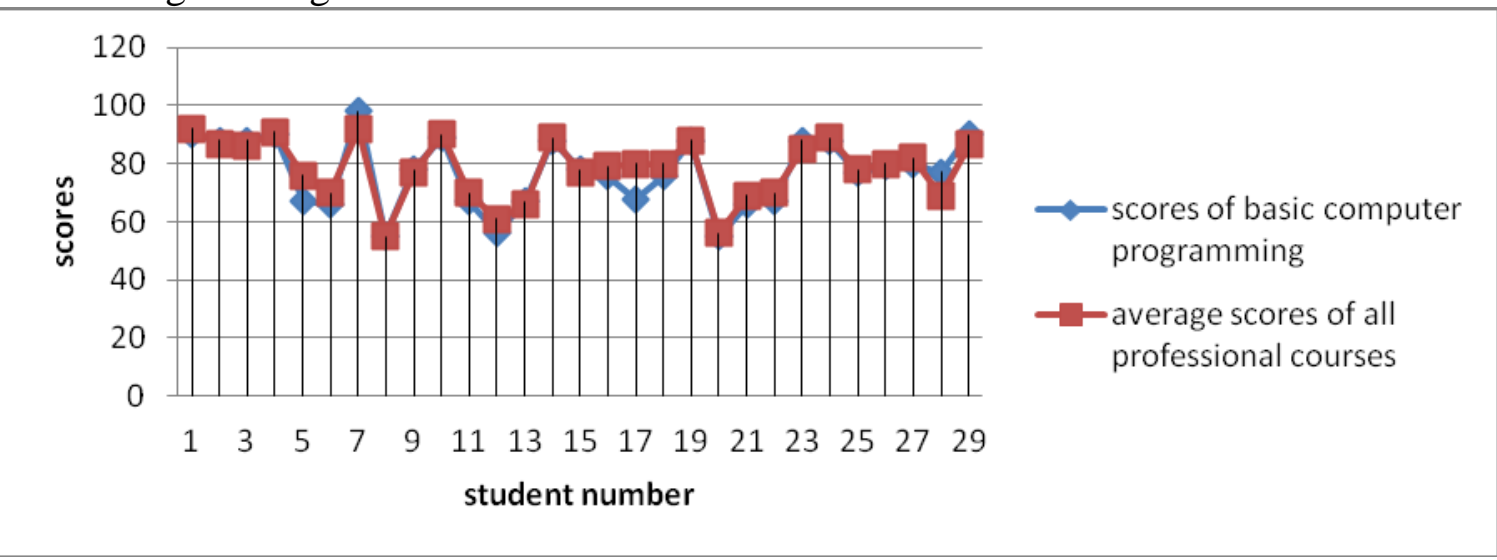

Fig.1. Correlations of Scores of basic computer programming and average scores of all professional courses of Class \#1

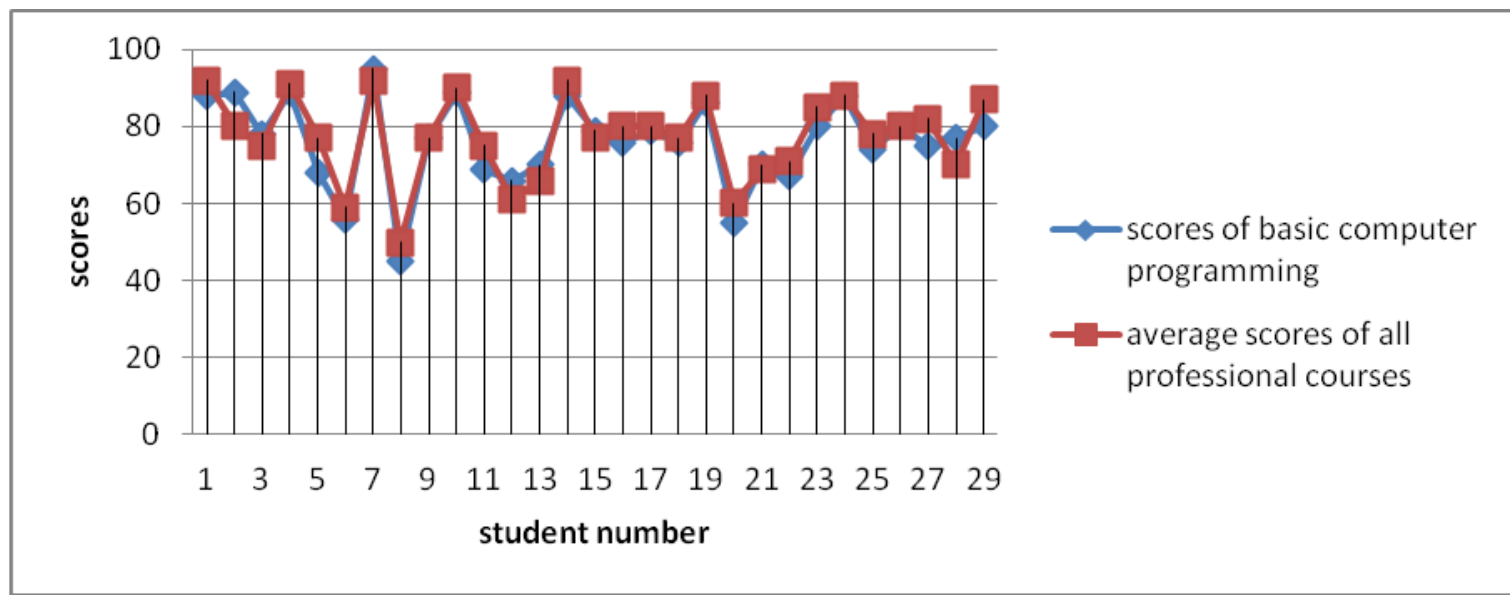

Fig.2. Correlations of Scores of basic computer programming and average scores of all professional courses of Class \#2

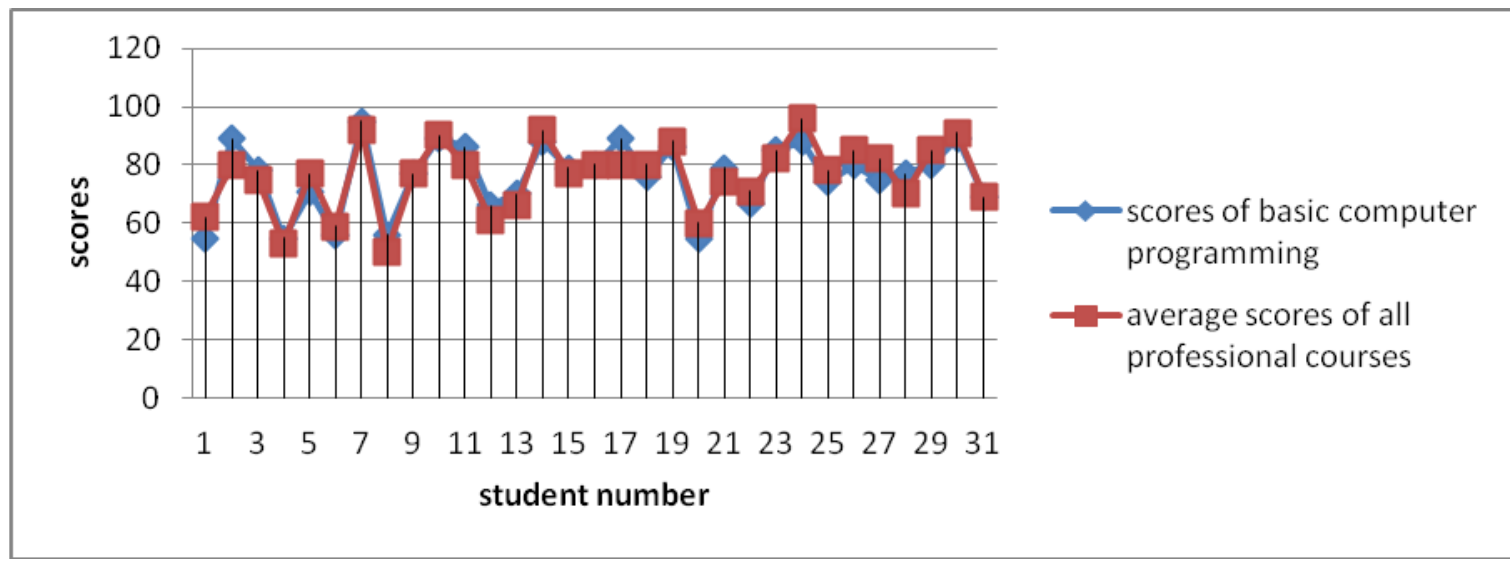

Fig.3. Correlations of Scores of basic computer programming and average scores of all professional courses of Class \#3 


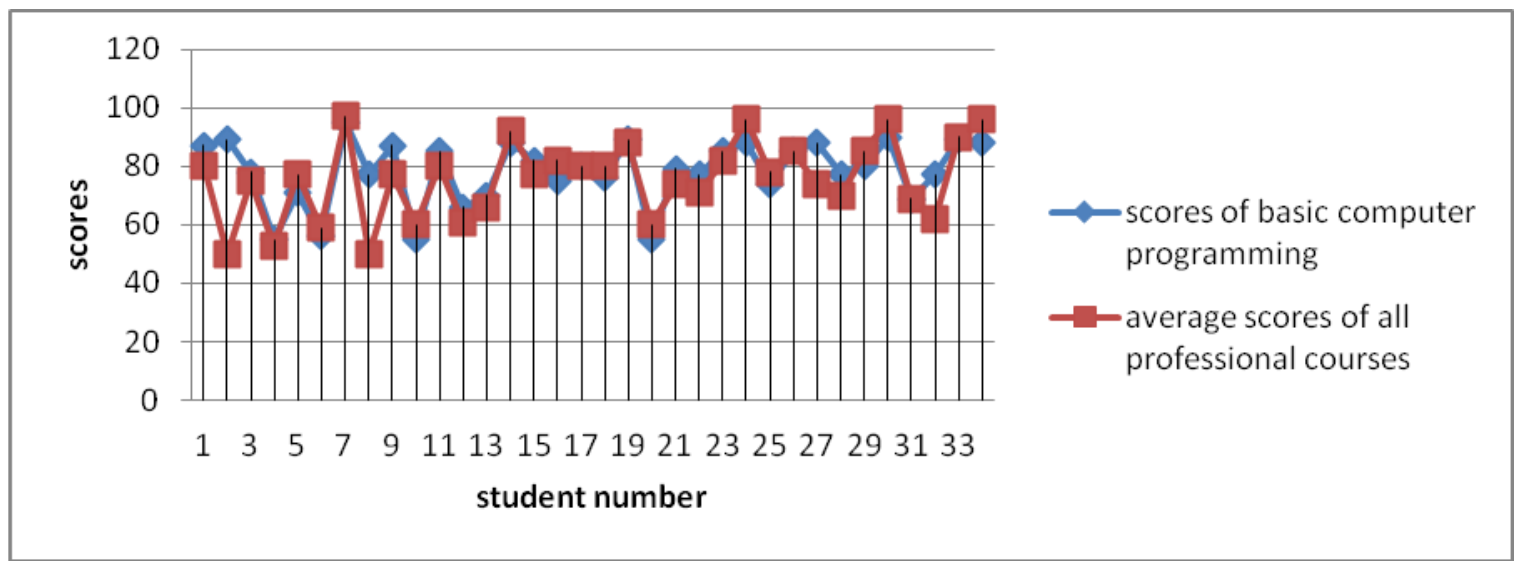

Fig.4. Correlations of Scores of basic computer programming and average scores of all professional courses of Class \#4

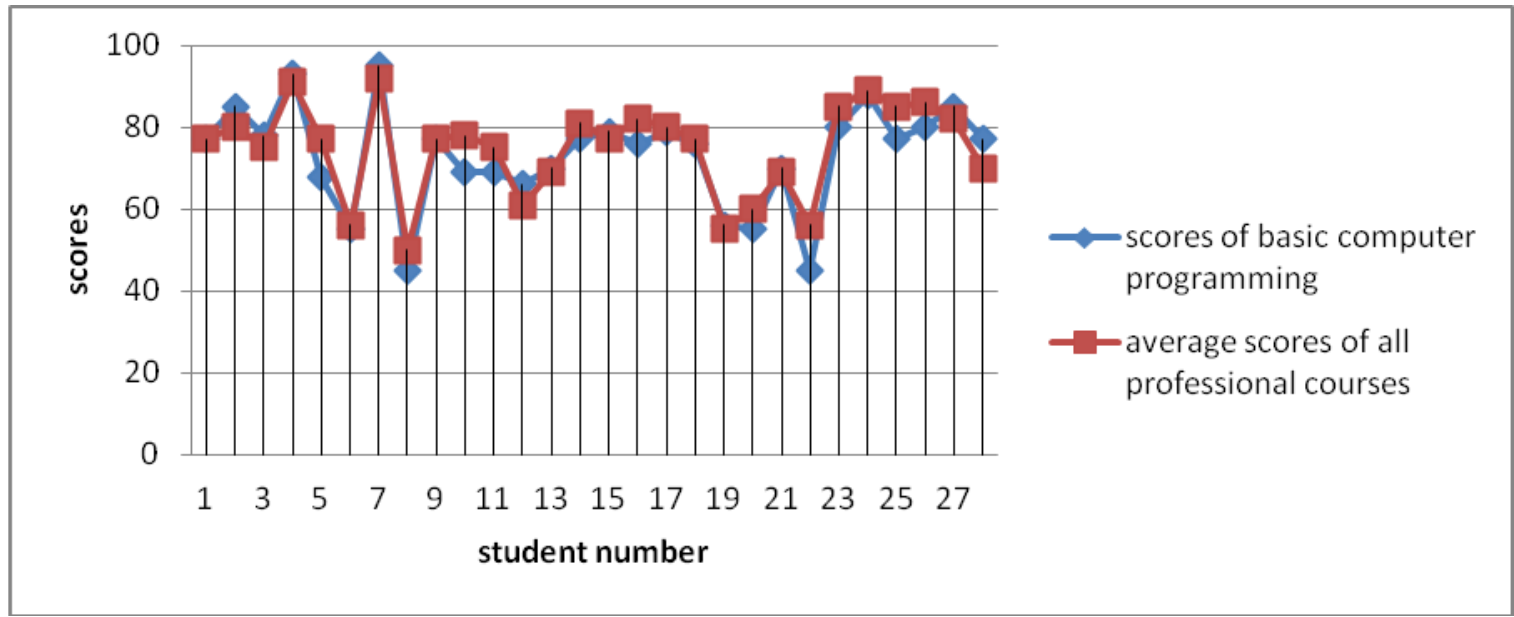

Fig.5. Correlations of Scores of basic computer programming and average scores of all professional courses of Class \#5

From Figure 1 to Figure 5, we can see that the change curve of all majors' academic performance is quite consistent with the change rule of their basic computer programming scores. From above we can see the importance of basic computer programming for students following computer courses, which can illustrate the importance of basic computer programming in the following learning process. Therefore, the responsibility and teaching level requirements of basic curriculum teachers should be higher, so the teachers of basic courses in the teaching management of the selection criteria should be higher, which requires higher standard and higher treatment because the learning enthusiasm of their participation in teaching management in a great degree related to the study of the course students and related subjects.

\section{A Course Teachers is a Class Teacher in the Class}

Class is the basic unit of school education and management. An excellent class group has a great educational role in the healthy development of each student $[8,9]$. Being a grass-root manager of a university, a class teacher is an important process in the teaching management. Class committee chosen by a class teacher is a key to a class to be outstanding.

But now most of the time of the college students every day is spent with their teachers, and a class teacher is often not the teachers teaching them. Therefore, a class teacher knows learning ability of students mainly by final exam scores of each semester. As a result, the comprehensive understanding of the learning ability of the students will have time delay and limitations, which leads to some deviation when selecting the monitor and class committee. Nowadays, the college students have 
distinct personality, but they are easily affected by the surrounding environment. When the selected monitor and class committee have strong learning ability, the whole class will have a correct study attitude and a strong atmosphere of learning will be formed; Otherwise, an incorrect study attitude of the monitor and class committee will have bad influence to other students in class, which leads to a wrong understanding of the study attitude of the whole class, such as low study enthusiasm, bad study atmosphere, etc. As a result, the scores of the whole class will be affected.

In order to illustrate the relationship between the scores of the monitor and the study committee member of a class and the scores of the whole class, we choose higher mathematics curriculum of the above 5 classes as an example. The comparison among the average score of each class, the score of the class monitor, and the score of the study committee member of each class is shown in Table 1. It can be seen from the table that the class monitor and the study committee member have a certain strong exemplary role in the whole class.

Table 1: Average score of each class, the score of the class monitor, and the score of the study committee member of each class

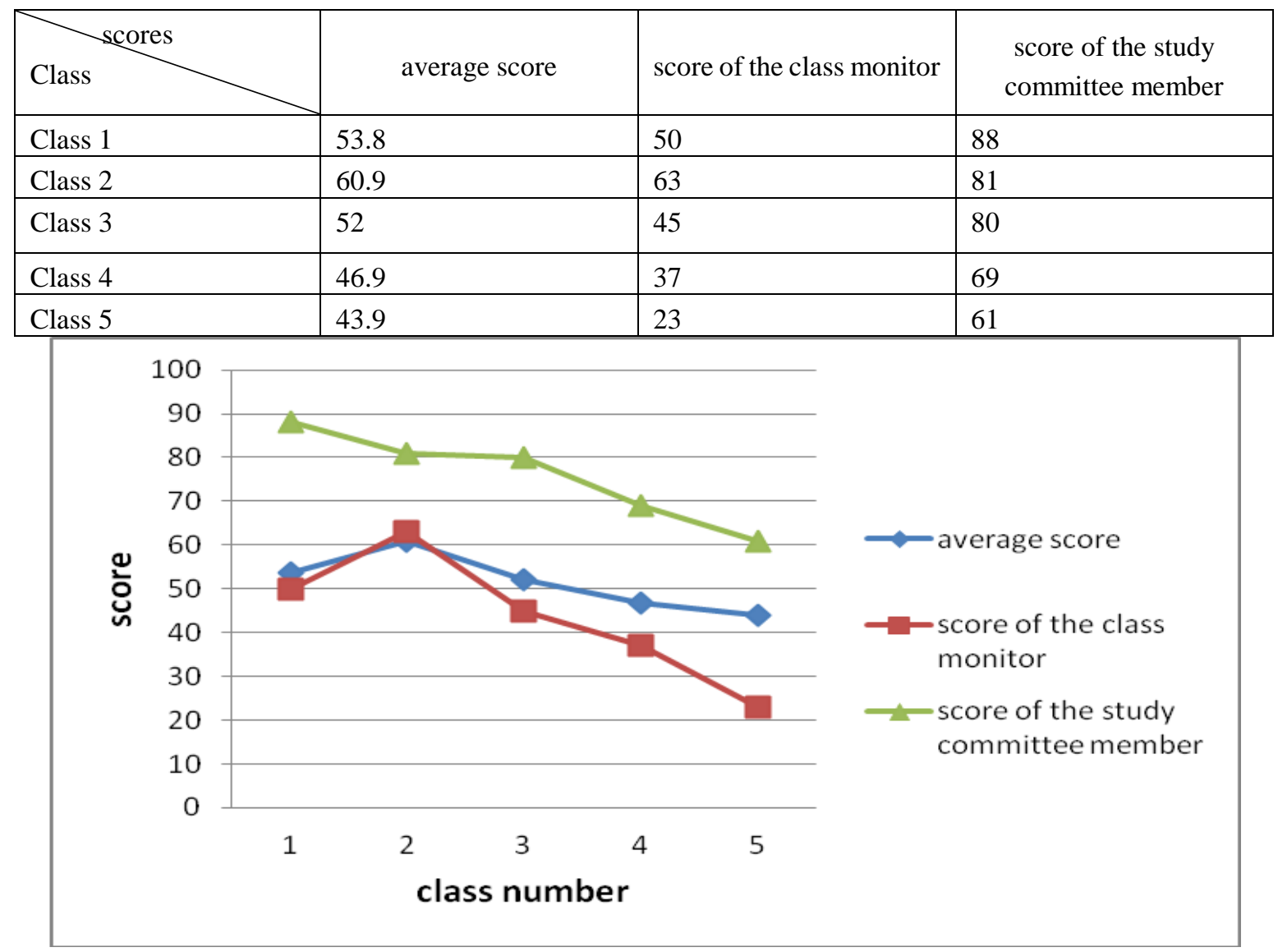

Fig.6 Correlations of average score of each class, the score of the class monitor, and the score of the study committee member of each class 1-class 5

\section{Conclusion}

During the teaching process, teachers can understand students' learning ability in a timely and clear way through students' learning attitude and learning performance of his or her course. If the teacher has a dual responsibility of not only teaching but also educating students and timely communicate with the class teacher, the class teacher can understand and grasp the students' learning attitude and learning ability timely and take actions to timely adjust the class learning atmosphere, which can 
guarantee the correct positive class learning atmosphere and maintain a good momentum of development of the class.

In short, teachers should pay more attention to the role of management in the process of teaching. Universities should give full play to their initiative and arouse their enthusiasm and interest to participate in the management of teaching. Universities should also change the phenomenon of teachers "just teaching in class regardless of the class management" and teachers should also have an active attitude of teaching management. Only through this way, the management of colleges and universities can have a good result and quality in the teaching aspects, which ultimately benefit all the teachers and students in the universities and colleges.

\section{Acknowledgement}

The work is supported by National Nature Science Foundation of China (No.11201002), Talent of Discipline and Specialty in Colleges and Universities of Anhui Province (No.gxbjZD54), Anhui Province Quality Engineering (No.2015zy073, No.2017ghjc229), Academic Leader Foundation (No.2014XXK06), Introduction of Talents Foundation of Anhui Xinhua University, and Colleges Nature Science Research Key Project of Anhui Province (No.KJ2015A325).

\section{References}

[1] M. Gu. Reflection on the reform of teachers' Education in China. Teacher Education Research, 2006, 18(6): 3-6.

[2] Y. Zhu. Reexamination of educational practice in teacher education. Teacher Education Research, 2007, 19(5): 35-39.

[3] C. Xi, H. Wang, N. Wang, Y. Duan, and J. Lv. The application of teaching and educating cases in Colleges and Universities. Journal of Shenyang Agricultural University (Social Sciences Edition), 2016, 18(2): 200-203.

[4] C. Bao, J. Zhang, X. Zhao, J. Zhu, and N. Hu. Reforming the classroom teaching mode to improve the quality of the basic course. China University Teaching, 3(2017) 59-62.

[5] L. Zhang, Y. Wei, H. Yan, T. Wang, and H. Li. An empirical study on the evaluation model of the teaching quality of basic courses in universities. Journal of Beijing University of Posts and Telecommunications(Social Sciences Edition), 2017, 19(2):103-110.

[6] X. Xia. The application of collaborative learning under the concept of CDIO in the teaching of program design course. Journal of Shaoguan University, 2017, 38(8):70-73.

[7] C. Qi. The programming teaching application research under the experience teaching mode.Zhejiang Normal University (2016)

[8] Q. Li. Some understanding of the unity and cooperation between the headmaster and the teachers of the class. Gansu Education, 11(2015)26.

[9] H. Dong and X. Liu. To make class teachers participate in class management. Shanxi Education(Management Edition), 1(2000)32.

[10] M. Wang. The cooperative function of teachers of the class in class management. Education Weekly, 40(2015)79. 